\title{
Perspectiva pós-religional e Budismo secular: Stephen Batchelor e a religião pós-metafísica
}

\author{
Post-religional perspective and secular buddhism: \\ stephen batchelor and the post-metaphysical religion
}

Leandro Marques Durazzo *

\begin{abstract}
Resumo
Este texto pretende apresentar uma das tendências contemporâneas que o budismo vem assumindo ao longo das últimas décadas, sobretudo no Ocidente, em face às mudanças trazidas a cabo pelo contexto globalizado e dinâmico das sociedades atuais. Tal tendência, a progressiva secularização de suas tradições e práticas, bem como a abertura à crítica e à refutação histórico-bibliográfica, ganha aqui seu catalisador na pessoa de Stephen Batchelor, renomado estudioso budista, ex-monge em diferentes ordens tradicionais - nomeadamente a tibetana e o zen da Coreia - e um dos mais destacados defensores da perspectiva secular do budismo contemporâneo. Buscaremos, ao longo desta comunicação, indicar o diálogo potencial que o budismo secular e as perspectivas secularizantes sobre as tradições culturais ortodoxas - apresenta com relação à temática pósreligional, como enunciada pela Associação Ecumênica de Teólogos do Terceiro Mundo e por Marià Corbí. Recorremos, para tal, a referências hermenêuticas modernizadoras e seculares da prática do Dharma, como advogada por Batchelor, entre outros.
\end{abstract}

Palavras-chave: budismo contemporâneo; budismo secular; secularização; Dharma; prática religiosa;

\begin{abstract}
This paper aims to present one of the contemporary trends on Buddhism, specially from the last decades in West, for its encounter with the globalized and dynamic context of present societies. This Buddhist trend, the progressive secularization of its traditions and practices, not to mention its increasing acceptance of historicaltextual refutation, finds in Stephen Batchelor - a former monk in two different Buddhist traditions, Tibetan and Korean Zen - a catalyzer and a well-known advocate of secular perspective to the contemporary Buddhism. Here we will present the potential dialogue between the Secular Buddhism - besides the secularizing perspectives over orthodox cultural traditions - and the post-religional subject, as proposed by Marià Corbí and the Ecumenical Association of Third World Theologians. For the purposes of this paper we will focus on the modernizing and secular hermeneutics on Dharma practice, as defended by Stephen Batchelor and others.
\end{abstract}

Keywords: contemporary buddhism; secular buddhism; secularization; dharma; religious practice.

Comunicação submetida em 05 de outubro de 2014 e aprovada em 17 de março 2015.

* Escritor e tradutor. Mestre em Letras. Doutorando em História e Cultura das Religiões na Universidade de Lisboa. País de origem: Brasil. E-mail: leandrodurazzo@gmail.com 
Tem-se como evidente, em se tratando de senso comum sobre as religiões, que o elemento definidor de uma estrutura religiosa é seu sistema de crenças e fé. Assim, um religioso - de praticamente qualquer denominação - seria aquele sujeito que, integrado a uma coletividade e/ou exposto a uma série de influências culturais e tradições estruturadas, professaria as mesmas crenças que seus pares.

Entretanto, como nota Marià Corbi quando analisa as condições contemporâneas das sociedades industriais,

o novo paradigma [pós-religional] não poderá estar submetido a nenhum sistema de «crenças», nem religioso, nem laico. Poderíamos dizer que é um paradigma «não crente». As sociedades que precisam mudar continuamente suas interpretações da realidade, por causa da contínua transformação de nossos conhecimentos científicos em todos os âmbitos da vida humana; que vivem da contínua criação tecnológica que altera constantemente nossos modos de vida, de trabalho, de organização e, por conseguinte, nossos sistemas de coesão e de finalidades: não podem ser crentes, porque as crenças fixam e as novas sociedades sobrevivem mobilizando todos os parâmetros de suas vidas. (CORBÍ, 2012, p. 256, tradução nossa).

Por paradigma pós-religional, o autor quer se referir - como têm feito diversos autores envolvidos com o diálogo teológico frente às sociedades contemporâneas (cf. EATWOT, 2012) - a uma nova condição axiológica com a qual somos confrontados, no mundo globalizado e de comunicações aceleradas, sempre que as instâncias da vida cotidiana, concreta e pragmática, se aproximam do que é chamado, ainda por Corbí, de qualidade humana profunda, ou seja, "o cultivo da dimensão absoluta e gratuita da realidade" (CORBÍ, 2012, p. 257, tradução nossa).

Fica claro, desde o princípio dessa argumentação, que o que se tem por pósreligional é uma compreensão humana - e, por isso, simbólica e hermenêutica, contingenciada pelas intimações socioculturais de seu tempo e espaço - das questões últimas da existência humana. Por isso, relacionadas às religiões e ao pensamento religioso; ainda por isso, relacionadas, como questões últimas da existência, a termos como fé e crença - para não mencionarmos as noções de transcendência. 
O que a passagem acima nos mostra é que, independente do histórico crente das religiões, a contemporaneidade - que precisa "mudar continuamente suas interpretações da realidade, por causa da contínua transformação de nossos conhecimentos científicos" - conduz as vivências religiosas, as vivências da qualidade humana profunda, para um novo lugar na paisagem sociocultural da humanidade. Não bastariam, para ser religioso, a profissão de fé e as crenças compartilhadas, estaticamente - ainda que nenhum sistema de crenças seja, por força da realidade social, estático - por um grupo; antes, seria necessária a dinamização da qualidade humana profunda frente aos desafios e mudanças típicos da contemporaneidade mutável e autoconsciente da mutabilidade - mesmo de seus pressupostos básicos, como é característico dos procedimentos científicos e tecnológicos.

A tradição a que nos referiremos, aqui, através da consideração de alguns pontos do pensamento de Stephen Batchelor, é a que tem sido denominada, desde alguns séculos no Ocidente, budismo. Uma de suas características centrais, em quase todas as diversas tradições culturais que se desenvolveram a partir das influências do Dharma do Buda, é o reconhecimento e compreensão da impermanência, ou seja, da constante e total mutabilidade das condições dos fenômenos. Considerando a impermanência de todos os fenômenos, somos instados também a considerar a impermanência - mesmo a fragilidade - das crenças e sistemas ortodoxos, rígidos, de pensamento. Batchelor, em consonância com o que tem sido chamado, sobretudo nos Estados Unidos ${ }^{1}$, de budismo secular, apresenta algumas reflexões que podem, primeiro, elucidar os pontos de contato da tradição do Dharma com as sociedades contemporâneas e, em segundo lugar, oferecer possibilidades de encarar essa própria tradição.

Tendo levantado a terminologia paradigma pós-religional, seguiremos com Corbí um pouco mais. Ele nos diz que "o novo paradigma deve possibilitar que

\footnotetext{
1 Ver, por exemplo, a Associação Budista Secular (Secular Buddhist Association), que há anos vem desenvolvendo uma rede de contatos e debates nas questões que aqui nos interessam. Seu programa de entrevistas, em formato de podcast, é um dos mais consolidados no panorama contemporâneo do budismo americano, tendo o próprio Stephen Batchelor participado de alguns de seus episódios. A própria associação define suas intenções como "uma aproximação natural e pragmática dos ensinamentos e práticas do budismo primitivo", cf. http://secularbuddhism.org/
} 
herdemos toda a sabedoria das religiões e tradições espirituais de nossos antepassados de toda a humanidade, sem que isso implique em nos tornar crentes, religiosos e submissos” (2012, p. 258, tradução nossa).

É justamente esse espírito que o budismo secular mantém em suas práticas e diálogos. Herdar a sabedoria e todo o desenvolvimento reflexivo, filosófico, pragmático e doutrinário das tradições budistas - sobretudo da Ásia Oriental sem que seja necessário, por implicações de autoridade e hierarquia, submeter-se a modelos culturais e modos de vida alienígenas. O budismo secular busca, por força de sua conformidade ao momento contemporâneo, não a submissão a quaisquer ensinamentos tradicionais do budismo oriental, mas sua prática e entendimento através de aproximações laicas, ocidentais e mesmo agnósticas no que diz respeito às crenças - de fundo indiscutivelmente cultural - em aspectos consolidados como karma, renascimento, planos metafísicos de existência, etc.

Aqui, vale passarmos ao que Stephen Batchelor tem a nos dizer no âmbito da prática contemporânea e ocidental das tradições budistas. Em seu Confession of a Buddhist Atheist (BATCHELOR, 2011)², uma autobiografia ensaística e especulativa, ele nos conta sua trajetória como monge no budismo tibetano e, depois, como monge zen em um mosteiro da Coreia do Sul, ao longo das décadas de 1970 e 1980. O resultado dessa peregrinação monástica e transcultural, antropológica em seu sentido profundo, foi a abertura de uma sensibilidade no que toca às condições do budismo no mundo atual, sobretudo em nossas sociedades industriais e tecnológicas, pautadas - quase sempre - por paradigmas laicos onde o debate público e o confrontamento de ideias se faz basal.

Atingindo o mesmo potencial crítico que podemos vislumbrar tanto no assim chamado budismo secular quanto na proposta pós-religional da EATWOT (Associação Ecumênica dos Teólogos do Terceiro Mundo, sigla em inglês), Batchelor destaca uma característica que julga fundamental e amplamente

2 Há uma tradução recente ao português, de 2012, publicada pela brasileira Editora Pensamento (Confissões de um ateu budista). Aqui, para fins de citação, utilizaremos a versão original em inglês. 
encontrada nas bases da tradição budista. Eis como tal característica é enunciada, no texto do autor:

Assim como um ourives testa o ouro, polindo-o, cortando-o e o queimando" diz uma famosa citação atribuída ao Buda, "deve você examinar minhas palavras. Não as aceite apenas baseado em sua fé em mim." Tal abertura à investigação crítica me impactou [...] como sendo central para todo o esforço do Budismo. Além disso, como tal questionamento é visto, junto da meditação e da ética, como parte do caminho da iluminação, ele deixa de ser um exercício acadêmico pedante e supérfluo. Em mim, essa forma de aproximação encontrou bastante apelo. Budismo, ao que parecia, era uma religião racional, cujas verdades apresentadas deveriam resistir aos testes da razão. (BATCHELOR, 2011, p. 33, tradução nossa).

A “abertura à investigação crítica”, à indagação e à proposição da dúvida quanto aos postulados emitidos, é parte do que faz, hoje, o budismo encontrar terreno fértil no debate público e mesmo científico. Vale dizer, como o próprio Batchelor esclarece, que tal criticidade não é - nem se propõe a ser - uma "verdadeira mensagem do Buda", ou o sentido último e indiscutível de sua doutrina. Conhecendo e reconhecendo que cada momento e cultura estabelece suas próprias bases de relacionamento tanto com a doutrina budista quanto com os expedientes pragmáticos e as práticas rituais e religiosas, o autor esclarece que tal postura secular só responde a uma urgência sociocultural localizada. Ele não propõe, assim, uma verdade budista, mas uma possibilidade de entender e praticar o Dharma a partir de uma coerência para a mentalidade contemporânea, inquiridora e secular. Nesse sentido, tal “inteligibilidade” doutrinária poderia ser comparada ao que, no budismo, é longa e largamente denominado upaya.

Este conceito, passível de ser traduzido como expediente, meios hábeis ou ensinamentos adaptados (MATSUNAGA, 1974, p. 51), designa justamente essa plasticidade buscada pelos budistas seculares no que diz respeito à modulação moderna e laicizante do Dharma. Não é de espantar, portanto, que a tradição budista pareça tão adaptável à mentalidade questionadora secular; o que o diverso histórico dos upayas - meios hábeis - é capaz de demonstrar, ao longo da história da religião, é que o Dharma possui expedientes de diálogo e integração às sociedades e culturas em que chega, fazendo uso - por processos históricos sempre 
contínuos e complexos - dos substratos culturais presentes nos territórios de chegada. Podemos pensar, por exemplo, nas diferentes modulações que o budismo chinês, tendo dialogado com as tradições nativas do taoísmo e confucionismo, apresenta em comparação com o budismo tibetano, que fez de seu encontro com a tradição xamânica Bon uma das formas de sua adaptação ao novo contexto.

A própria utilização do termo secular, não enfatizado na proposta teológica pós-religional, por exemplo, evidencia uma articulação de pensamento que Batchelor explicita no início de seu artigo A Secular Buddhism (2012). Ele parte de uma consideração tripla do termo, estabelecida da seguinte maneira: 1) secular como contraposto a religioso, no exato sentido dado pelo senso comum contemporâneo; como o próprio Batchelor ilustra, podemos tomar como exemplo a divergência de opiniões em temas polêmicos - a existência de Deus, por exemplo que muitas vezes é veiculada pela mídia. Nos debates sobre tais temas, não é raro vermos uma opinião religiosa no assunto, normalmente eclesiástica e/ou confessional, ter sua posição contraposta a uma outra perspectiva sobre o assunto, uma perspectiva secular. Neste primeiro caso, diz o autor, não há precisão no que diz respeito aos termos secular e religioso, mas tal precisão não é requerida para o entendimento da situação; 2) secular a partir de sua raiz latina, etimologicamente significando a temporalidade presente (saeculum, “esta era”, "este século”). Nesta acepção, a noção de secularidade nos direciona para a consideração sobre nossa realidade material e temporal, abrangendo "nossa experiência pessoal, social e ambiental de vida neste planeta” (BATCHELOR, 2012, p. 87, tradução nossa); 3) por fim, secular tomado no sentido histórico-sociológico evidenciado pela distinção de poderes e autoridade no Ocidente, historicamente transferidos das esferas religiosas para o poder público relacionado ao Estado.

A segunda acepção elencada por Batchelor - o século como temporalidade presente - é uma das que consideramos mais frutíferas a este debate. Isso porque, embora nem a distinção genérica secular/religioso, nem o processo histórico de transferência de poder para as mãos do Estado sejam desimportantes, a compreensão de uma secularidade envolvida com o tempo presente e suas ações 
orientadas para os processos socio-histórico-ambientais são respostas eminentemente dirigidas aos dilemas que enfrentamos, hoje, enquanto sociedade global tecnológica3.

Neste aspecto específico, Stephen Batchelor concordaria com críticas budistas aos modelos desenvolvimentistas modernos, que - via de regra desconsideram os impactos ambientais e as desigualdades socioambientais em escala global. Em artigo intitulado Bolhas coletivas de ilusão (Collective Bubbles of Delusion), o também professor budista e escritor David R. Loy aponta uma das mazelas delusórias que nossa realidade social planetária pode acarretar. Diz, atacando as posições negacionistas no que diz respeito à mudança climática em curso, que

O que talvez seja mais desconcertante na negação da mudança climática [...] é que há pouco, se é que há algum, benefício real em negá-la, exceto para aqueles que detêm e administram as corporações de combustíveis fósseis. Negar o aquecimento global não é apenas uma fantasia coletiva problemática; é uma crença falsa, manipulada através de uma cara e engenhosa propaganda, por pessoas que, no geral, sabem que ela é uma ficção perigosa, mas que estão mais interessadas nos lucros a curto prazo que podem ser gerados com a continuidade da extração de combustível fóssil para a atmosfera. $\mathrm{O}$ resultado disso não é apenas uma bolha coletiva de ilusão: é uma bolha intencionalmente perpetuada por corporações poderosas e bilionários - um exemplo da delusão institucionalizada. (LOY, s/d, tradução nossa).

Nosso autor, Stephen Batchelor, não chega a desenvolver tais críticas ou reflexões socioambientais, mas a acepção de secular que nos apresenta, sendo intrinsecamente orientada a este mundo e a esta época, oferece bases epistemológicas que acabam por se afinar às críticas acima expostas.

Se Batchelor não se empenha em apontar as limitações e desenvolvimentos negativos de uma delusão institucionalizada, como faz David Loy, ele se dedica sinceramente a sugerir desenvolvimentos potencialmente negativos que uma institucionalização soteriológica do budismo acarretaria. Com isso queremos dizer que, demonstrando uma dependência do budismo para com as dimensões

3 Ver, por exemplo, o artigo de Dipesh Chakrabarty intitulado O clima da história: quatro teses (2013), em que ele analisa a dimensão geológica da ação humana sobre as mudanças climáticas e ambientais do planeta. 
soteriológica, epistemológica e cultural da Índia antiga - onde se originou -, Bachelor ousa avançar hermeneuticamente até campos pouco explorados pelas tradições.

Diz o autor, por exemplo, que a estrutura de pensamento indiano que favoreceu o surgimento do budismo, com suas concepções cíclicas de criação e renascimento, com os diferentes reinos de existência e, sobretudo, com as noções de karma e libertação do ciclo de nascimentos e mortes - o nirvana, objetivo último dessa visão soteriológica de mundo cíclico -, não possui substrato cultural no ocidente moderno para se sustentar.

Esta negação de importância a noções consideradas fundamentais ao budismo, a saber, karma e nirvana, é uma das características que mais comumente servem de base às críticas a Batchelor. Entretanto, o pensamento secular do budismo que vem se desenvolvendo nas últimas décadas, no Ocidente, não é capaz de se furtar a esses questionamentos. Não tendo uma tradição cultural de tempo cíclico, nos termos indianos, a aceitação de tais noções orientais não seria uma incorporação cultural, mais do que uma prática filosófico-pragmática, como querem os secularistas?

Crer que existam realidades supramateriais e diversos renascimentos, e que a iluminação a que o Dharma conduz seja a superação deste ciclo metafísico, no entendimento da perspectiva secular, não passa disso, justamente: de consideração metafísica. O próprio Batchelor chega a essa conclusão, e argumenta que é impossível demonstrar ou refutar, nos moldes racionais modernos a que estamos culturalmente acostumados, uma asserção metafísica. Exigir a crença em um ciclo de renascimentos e na potencial libertação deste ciclo é, segundo o autor, análogo a exigir a crença indemonstrável - também irrefutável - em qualquer dimensão metafísica.

É, ainda, estabelecer que a prática do Dharma dependeria da crença em tais verdades indemonstráveis. Em outras palavras, seria - como tem sido, ao longo 
dos séculos e das diversas tradições budistas - exigir fé em verdades apresentadas, mais do que convidar para a prática de tarefas pragmáticas e Dharmicamente orientadas, por assim dizer.

A ênfase dada a essa distinção, entre verdades a serem aceitas e tarefas a serem cumpridas, aparece já em Budismo sem crenças (Buddhism Without Beliefs), uma obra de Batchelor datada de 1997. Nesse livro, ele tenta "escrever um livro sobre budismo em inglês coloquial, evitando o uso de palavras estrangeiras, termos técnicos, listas e jargão.” (1997, p. XI, tradução nossa). Dada essa intenção, o livro não faz referência a terminologias técnicas de tradições meditativas, tampouco a bibliografias especializadas e citações abundantes de termos em páli ou sânscrito, dois dos idiomas que se consideram mais antigos nos registros da doutrina.

Sem ressaltar quaisquer exigências de crença metafísica, mesmo as soteriologicamente metafísicas, como a superação do samsara (o ciclo de nascimento e morte) através do nirvana (sua libertação), o texto apresenta e orienta práticas e exercícios meditativos, bem como oferece bases para o entendimento do Dharma. Considerando que, "historicamente, o budismo tendeu a perder sua dimensão agnóstica em favor de uma institucionalização religiosa" (1997, p. 16, tradução nossa), Batchelor procura apresentá-lo de forma não institucionalizada, por mais que conheça e domine algumas das tradições institucionais que procura superar - superar não como se elas estivessem erradas em si mesmas, mas apenas na medida em que não correspondem mais, por questões socioculturais de nossa época, a visões de mundo fluidas e facilmente aceitáveis por nossa mentalidade crítica.

O que dizíamos ser uma distinção entre verdades a crer e tarefas a realizar, embora surja já em Budismo sem crenças, é mais bem explicitada - e, mesmo, relida e criticada - no artigo acima mencionado, A Secular Buddhism (2012). Nele, Batchelor retoma a questão de modo mais acadêmico, embasando-se em diversos textos e pesquisas em estudos budistas. Referindo-se às quatro nobres verdades - conteúdo do que é tradicionalmente tido como o primeiro sermão do 
Buda após sua iluminação -, mostra-nos que não deve ter havido, em versões mais antigas desse texto, a palavra verdade como título ou tema. As consequências dessa modificação textual, para a prática budista, seriam enormes. Diz o texto:

Essa tendência se torna ainda mais pronunciada quando "verdade" passa a ser qualificada como sendo "última" (paramattha) ou meramente "convencional" (samutti). Embora essa doutrina de duas verdades seja central para o pensamento de todas as ortodoxias budistas, os termos "verdade última" e "verdade convencional" não aparecem sequer uma vez nos Pitakas (cestos) Sutta ou Vinaya do cânone páli. Ainda assim, para a maioria das escolas budistas atuais - inclusive a Theravada -, a iluminação é compreendida como o alcance direto de um entendimento sobre a natureza de tal verdade última. Privilegiar a "verdade", eu diria, é um dos indicadores-chave de como o dharma foi gradualmente transformado, de uma libertadora prática do despertar, em um sistema religioso de crenças denominado budismo. (BATCHELOR, 2012, p. 92-93, tradução nossa).

Aqui, temos claramente uma crítica embasada a toda uma tradição religiosa que se estende desde séculos. Porque, diria Batchelor, se não existem quatro nobres verdades no ensinamento do Buda, mas apenas quatro, a qualificação doutrinária dessas palavras podem ser enormemente modificadas.

Atentemos para a questão colocada: tradicionalmente, o budismo diz que as quatro nobres verdades são 1) a identificação da existência com o sofrimento, 2) a causa do sofrimento, que é o apego, 3) a possibilidade de libertação do sofrimento e 4) o caminho pelo qual tal libertação é atingida. Batchelor considera que esta formulação, apresentada desse modo por quase todas as tradições budistas, coloca mal os termos do ensinamento. Ao longo do artigo, demonstra que as quatro nobres verdades indicam mais um sistema de crenças do que uma demonstração experimentável do Dharma do Buda.

O ponto nodal, ao que parece, é a consideração de que as formulações tradicionais (“a existência é sofrimento", por exemplo, como primeira nobre verdade) não representariam o ensinamento nirvânico do Buda, mas sim uma argumentação retórica elaborada ao longo dos séculos para justificar a soteriologia metafísica indiana, à qual já nos referimos. A constatação desse desvio doutrinário- 
enunciativo, por assim dizer, ganha força quando Batchelor chama ao debate o filólogo britânico K. R. Norman, referindo-se a um artigo de 1992 em que ele atesta não haver, na versão mais antiga do sutra do primeiro ensinamento do Buda, “a palavra ariya-sacca (nobre verdade)" (NORMAN apud BATCHELOR, 2012, p. 92, tradução nossa), tendo sido incorporada ao texto apenas posteriormente.

Com essa descoberta, Batchelor sugere uma modificação na formulação das quatro "coisas" - já não mais nobres verdades -, inclusive modificando sua sequência causal e argumentativa. Em vez de falar sobre verdades a serem aceitas e cridas, ele passa a considerar os quatro termos como noções a serem realizadas. Tarefas, portanto. É assim que passa a ser formulada, na concepção secular e nãometafísica de Stephen Batchelor, os quatro termos do primeiro discurso: 1) a existência do sofrimento; 2) o surgimento do apego, já não mais visto como causa do sofrimento, mas como sua consequência; 3) a cessação do apego, considerado aqui como ponto de parada e suspensão do apego à sensação/mentalidade sofredora; 4) o caminho autocentrado e não apegado às tendências instintivas e habituais anteriores.

Existe uma importante modificação aqui, evidenciada pelo deslocamento dos vínculos causais. Batchelor aprofunda essa modificação, lançando mão de referências textuais e doutrinárias, às quais não nos ateremos. O que mais interessa a nosso texto, por ser o fundamento da disposição secular que esse budismo contemporâneo vem assumindo, é o deslocamento da aceitação de nobres verdades para a prática de determinadas tarefas. A argumentação continua apontando a distinção fundamental entre crenças metafísicas - aceitação de uma verdade pré-apresentada ("vida é sofrimento") - e práticas verificáveis, pragmáticas e cotidianas.

Tais verificações, segundo esse pensamento, indicam o que segue: existe o sofrimento, o qual devemos conhecer e compreender enquanto dado; a tarefa a ser realizada, portanto, é sua aceitação. Quando não nos abrimos a essa compreensão profunda, a tendência é que nos apeguemos às reações habituais que surgem do contato com o sofrimento - por exemplo, buscar o afastamento e/ou a denegação 
daquilo que nos desagrada; a tarefa, aqui, seria suspender tais reações habituais, para que o apego às condições de sofrimento não se reproduzissem indefinidamente. Tendo compreendido o sofrimento e alcançado uma disposição tal que não mais reagimos a ele inconsciente ou instintivamente, somos levados à possibilidade de sua cessação; aqui, a tarefa seria efetivamente estancar o sofrimento, já que no passo anterior fomos capazes de reconhecer nossas reações habituais e deixá-las de lado. Por fim, tendo compreendido o sofrimento, deixado de lado nossas reações habituais e cessado o sofrimento - que o apego aprofundava -, chegamos ao que pode ser visto como o primeiro passo do nobre caminho óctuplo - assim chamado, mas deixamos a dúvida levantada sobre se a nobreza de tal caminho não seria, também, apenas um dado posterior e retórico. Caminho de oito passos, portanto.

Stephen Batchelor cunha o acrônimo inglês ELSA, para essa reformulação argumentativa. Cada uma das letras visa orientar a conduta mais recomendável no que diz respeito a essa nova visão de mundo, baseada nas quatro tarefas do Dharma, no discurso do Buda iluminado. ELSA, portanto, refere-se a Embrace (aceitar, compreender), Let Go (deixar de lado), Stop (parar) e Act (agir). A mudança levada a cabo, tanto na argumentação quanto nos vínculos causais dos quatro termos, reorienta a compreensão da prática budista, transferindo-a de uma série de enunciados metafísicos - "existência é sofrimento", dado que a estrutura soteriológica de base permaneceria com suas bases cíclicas indianas - para uma apresentação ética de postulados de conduta.

O budismo secular, não mais metafísico em seu sentido anterior, parece oferecer uma visão de mundo pautada em pressupostos diferentes. Como as sociedades tecnológico-industriais que forçam a teologia a se mutar em pósreligional, o pensamento secular do budismo contemporâneo, ocidental e em diálogo com as ciências e reflexões críticas, pode ser o início de uma nova modulação para o Dharma. Não é difícil de compreender que todas as formas tradicionais de budismo, sobretudo na Ásia oriental, foram moldadas não apenas 
pelas "verdades" de suas práticas budistas, mas também - e, talvez, sobretudo pelas contingências e intimações socioculturais de seus diferentes tempos históricos e localizações geográficas. O budismo secular seria, assim, a tentativa de uma nova adequação das práticas tradicionais a novos territórios, novos tempos e novas urgências e questionamentos.

Stephen Batchelor sugere que a secularização do budismo, de suas práticas e pressupostos doutrinários, possa talvez não ser a degenerescência de sua vitalidade, o fim de sua validade enquanto tradição espiritual. Através da constante crítica, reformulação e do estudo aprofundado de questões postas em debate, é possível que o processo que vemos em curso, hoje, seja sim o enfraquecimento das ortodoxias tradicionais da religião, mas também o nascimento e fortalecimento de uma nova modalidade cultural da prática do Dharma, mais afinada às exigências de nossos tempos, mentes e substratos culturais.

\section{REFERÊNCIAS}

BATCHELOR, Stephen. Buddhist Without Beliefs. New York: Riverhead Books, 1997.

BATCHELOR, Stephen. Confession of a Buddhist Atheist. New York: Spiegel \& Grau, 2011.

BATCHELOR, Stephen. A Secular Buddhism. In: Journal of Global Buddhism 13, 2012, p. 87-107. Disponível em: http://www.globalbuddhism.org/13/batchelor12.pdf.

CHAKRABARTY, Dipesh. O clima da história: quatro teses. In: SOPRO 91, 2013. Disponível em: http://www.culturaebarbarie.org/sopro/n91s.pdf.

CORBÍ, Marià. Elementos constitutivos del Paradigma Pos-religional. In: EATWOT's VOICES: v. 35, n. 2012/1, jan/mar 2012, p. 255-259.

EATWOT. Para um paradigma pós-religional? Consulta Teológica Latino-americana sobre religião. In: EATWOT's VOICES v. 35, n. 2012/1, jan/mar 2012. Disponível em: http://internationaltheologicalcommission.org/VOICES/VOICES-2012-1.pdf.

LOY, David. R. Collective Bubbles of Delusion. In: Ecological Buddhism. s/d. Disponível em: http://www.ecobuddhism.org/wisdom/editorials/bod

MATSUNAGA, Alicia; MATSUNAGA, Daigan. The Concept of Upaya in Mahayana Buddhist Philosophy. In: Japanese Journal of Religious Studies, 1/1, March 1974, p. 5172. Disponível em: http://nirc.nanzan-u.ac.jp/nfile/2297. 